\title{
Fleck corneal dystrophy
}

INSERM

\section{Source}

INSERM. (1999). Orphanet: an online rare disease and orphan drug data base. Fleck corneal dystrophy. ORPHA:98970

Fleck corneal dystrophy (FCD) is a rare generally asymptomatic form of stromal corneal dystrophy (see this term) characterized by multiple asymptomatic, non-progressive opacities disseminated throughout the corneal stroma with no effect on visual acuity. 